\title{
Carbohydrate to Itaconic Acid Conversion by Aspergillus terreus and the Evaluation of Process Monitoring Based on the Measurement of $\mathrm{CO}_{2}$
}

\author{
Nándor Nemestóthy ${ }^{1}$ • Péter Komáromy ${ }^{1}$ • Péter Bakonyi ${ }^{1} \cdot$ András Levente Tóth $^{1}$ · Gábor Tóth ${ }^{1} \cdot$ László Gubicza $^{1}$. \\ Katalin Bélafi-Bakó ${ }^{1}$
}

Received: 14 February 2019 / Accepted: 24 June 2019 / Published online: 26 June 2019

(c) The Author(s) 2019

\begin{abstract}
In this work, itaconic acid (IA) was produced biotechnologically by Aspergillus terreus fungal strain from glucose. The performance of the batch fermentation was kinetically assessed and the maximal IA production potential, maximal production rate and lag-phase time were determined as $28.1 \mathrm{~g} / \mathrm{L}, 3.83 \mathrm{~g} / \mathrm{L}$ day and 1.52 days, respectively. In addition, the bioprocess was evaluated based on the most frequently used parameters, in particular IA titer $(26.3 \mathrm{~g} / \mathrm{L})$, yield $(0.22 \mathrm{~g} / \mathrm{g}$ substrate $)$ and productivity $(0.1 \mathrm{~g} / \mathrm{L} \mathrm{h})$, which were comparable to the already published literature. Furthermore, an on-line monitoring system was installed to the fermenter in order to measure the $\mathrm{CO}_{2}$ content of the bioreactor off-gas. Actually, it was indicated by the results that the $\mathrm{CO}_{2}$ production could have a linear-like relationship with the quantity of fungal biomass. Hence, the data collected in such a way may have the potential to establish an alternative methodology for the monitoring of biomass growth in the course of the biological transformation taking place.
\end{abstract}

\section{Graphic Abstract}<smiles>OC1COC(O)C(O)C(O)C1O</smiles>

Glucose

$+$

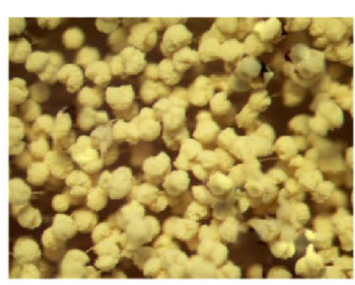

A. terreus

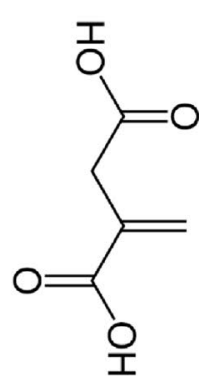

Itaconic acid
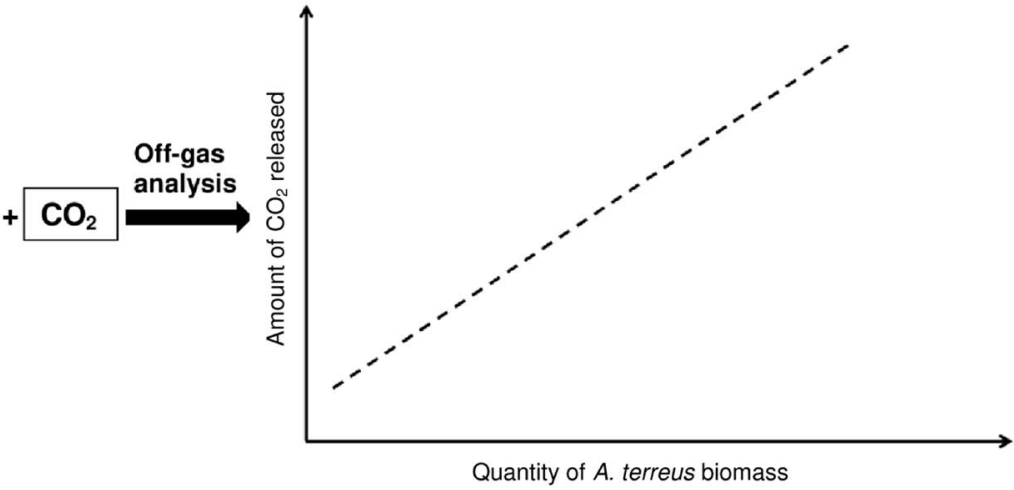

Keywords Itaconic acid $\cdot$ Aspergillus terreus $\cdot$ Glucose $\cdot$ Process monitoring $\cdot$ Off-gas analysis

Péter Bakonyi

bakonyip@almos.uni-pannon.hu

1 Research Institute on Bioengineering, Membrane Technology and Energetics, University of Pannonia, Veszprém, Egyetem ut 10, 8200, Hungary

\section{Statement of Novelty}

The novelty of this investigation is the findings presented for the first time using real-time bioreactor off-gas analysis as methodological approach to follow biomass growth during 
itaconic acid fermentation, which can thus have the potential to contribute to the international knowledge and further expansion of the research area.

\section{Introduction}

Itaconic acid (IA) is a $\mathrm{C}_{5}$-dicarboxylic acid, considered as a platform chemical to produce various substances of industrial relevance [1]. As a matter of fact, IA, as a precursor/ and building block, can be converted into plastics, latexes, absorbents $[1,2]$. As of now, the attractive way to generate IA is the biocatalytic route, mediated by living microorganisms, in particular filamentous fungi such as A. terreus [3]. In submerged fermentation systems, A. terreus has been reported as an efficient strain for IA mass production on carbohydrate sources, mainly glucose [4]. Nevertheless, other starting materials e.g. sucrose, lactose, corn syrup, molasses, lignocellulosic- and starchy-hydrolysates could also be suitable [5-8]. Sugars such as these mentioned can be derived in the biorefinery concept via the processing of plant biomass and thus, are considered sustainable resources $[9,10]$.

The multi-step metabolic pathways for biological synthesis of IA in Aspergillus from glucose are linked to the tricarboxylic acid (TCA) cycle, since in the end, itaconate is formed intracellularly from cis-aconitate (a TCA intermediate) by the aid of CadA decarboxylase enzyme [11]. By subsequent transportation outside the cell, IA can be recovered from the broth by technologies such as membrane filtration and electrodialysis [12-15]. Although A. terreus has been proven as the most promising candidate for IA production, the actual bioprocess performance is highly-dependent on the environmental settings, in terms of substrate concentration, $\mathrm{pH}$, temperature, media composition with respect to $\mathrm{N}$-sources as well as the presence/absence of certain minerals, dissolved oxygen levels, stirring rate, etc. [16-19]. On that matter, to track how efficiently the biosynthesis proceeds under given bioreactor operating conditions, the most essential information can be acquired from the fermentation kinetics with special interest on substrate consumption, IA (as product) formation and biomass growth.

Usual off-line methods to follow biomass growth with respect to filamentous fungi can include (i) the determination of specific metabolites such as ergosterol [20,21] and (ii) spectrophotometric turbidity, which is based on the amount of dry cell weight found in a given volume of culture medium [22]. Although this latter is considered quite fast compared to direct measurement of biomass dry weight, depends a lot on sample pretreatment conditions, especially homogenization affecting largely the degree of hyphal fragmentation. Supportive conclusions were drawn by Yoon et al. [23], finding that optical density (OD) values were significantly influenced by morphological structures of filaments. Thus, sample treatment has notable effect on the obtainable relationship between dry cell weight and OD. Besides, changes of biomass weight in the bioreactor could be estimated based on indirect conductivity with principles underlying on the absorption of metabolically-released $\mathrm{CO}_{2}$ in alkaline solution [24, 25].

In the current work, apart from the evaluation of IA production experiences from glucose substrate using A. terreus, our first results obtained with the continuous monitoring of $\mathrm{CO}_{2}$ released during the fermentation of IA are also discussed. It was aimed to evaluate the observations by comparing the experimental data with typical kinetic profiles of batch microbial conversions and thus, imply what potential of the real-time $\mathrm{CO}_{2}$ measurement (as an alternative methodology) may have in the monitoring of this bioprocess with respect to the biomass growth as key-parameter.

\section{Materials and Methods}

\section{Inoculum}

In this study, A. terreus NRRL 1960 was used as a biological catalyst proven to generate itaconic acid [17, 26, 27]. The strain was maintained at $37{ }^{\circ} \mathrm{C}$ regularly on Petri-plates with solid broth containing the following ingredients $(\mathrm{g} / \mathrm{L})$ : glucose-10; $\mathrm{NaCl}-20$, potato dextrose agar $-40, \mathrm{pH} 5$. To inoculate the bioreactor, liquid cultures $(\mathrm{pH} 3)$ were prepared (72 $\mathrm{h}$ ) in shaking incubator (150 rpm agitation rate) based on the following recipe $(\mathrm{g} / \mathrm{L})$ : glucose $-10, \mathrm{KH}_{2} \mathrm{PO}_{4}-0.1$, $\mathrm{NH}_{4} \mathrm{NO}_{3}-3, \mathrm{MgSO}_{4} \times 7 \mathrm{H}_{2} \mathrm{O}-1, \mathrm{CaCl}_{2} \times 2 \mathrm{H}_{2} \mathrm{O}-5, \mathrm{FeCl}_{3}$ $\times 6 \mathrm{H}_{2} \mathrm{O}-1.67 \times 10^{-3}, \mathrm{ZnSO}_{4} \times 7 \mathrm{H}_{2} \mathrm{O}-8 \times 10^{-3}, \mathrm{CuSO}_{4}$ $\times 7 \mathrm{H}_{2} \mathrm{O}-1510^{-3}$. Dry cell weight $(\mathrm{DCW})$ was determined by harvesting the fungal biomass on cellulose filter paper (Whatman qualitative filter paper, Grade 1). Thereafter, the paper together with the filtrate was dried in oven until the mass got constant and the actual quantity of biomass (e.g. appearing in Fig. 4) was determined by subtracting the mass of the dry filter paper [28]. For the experiments, (analytical standard grade) glucose was purchased from Sigma-Aldrich.

\section{Bioreactor Setup for Itaconic Acid Production}

This work was carried out in Lambda Minifor bioreactor system (Fig. 1a), similar to our recent work [29]. The fermenter was operated in batch mode with a medium (sterilized prior to use in autoclave) described for inoculum preparation ("Inoculum" section), expect in terms of the glucose (substrate) concentration, which was adjusted to $120 \mathrm{~g} / \mathrm{L}$. The working volume of the reactor was 1.8 $\mathrm{L}$ and the inoculum rate was $5 \%$ to start-up the process. Given that IA formation with $A$. terreus requires aerobic 

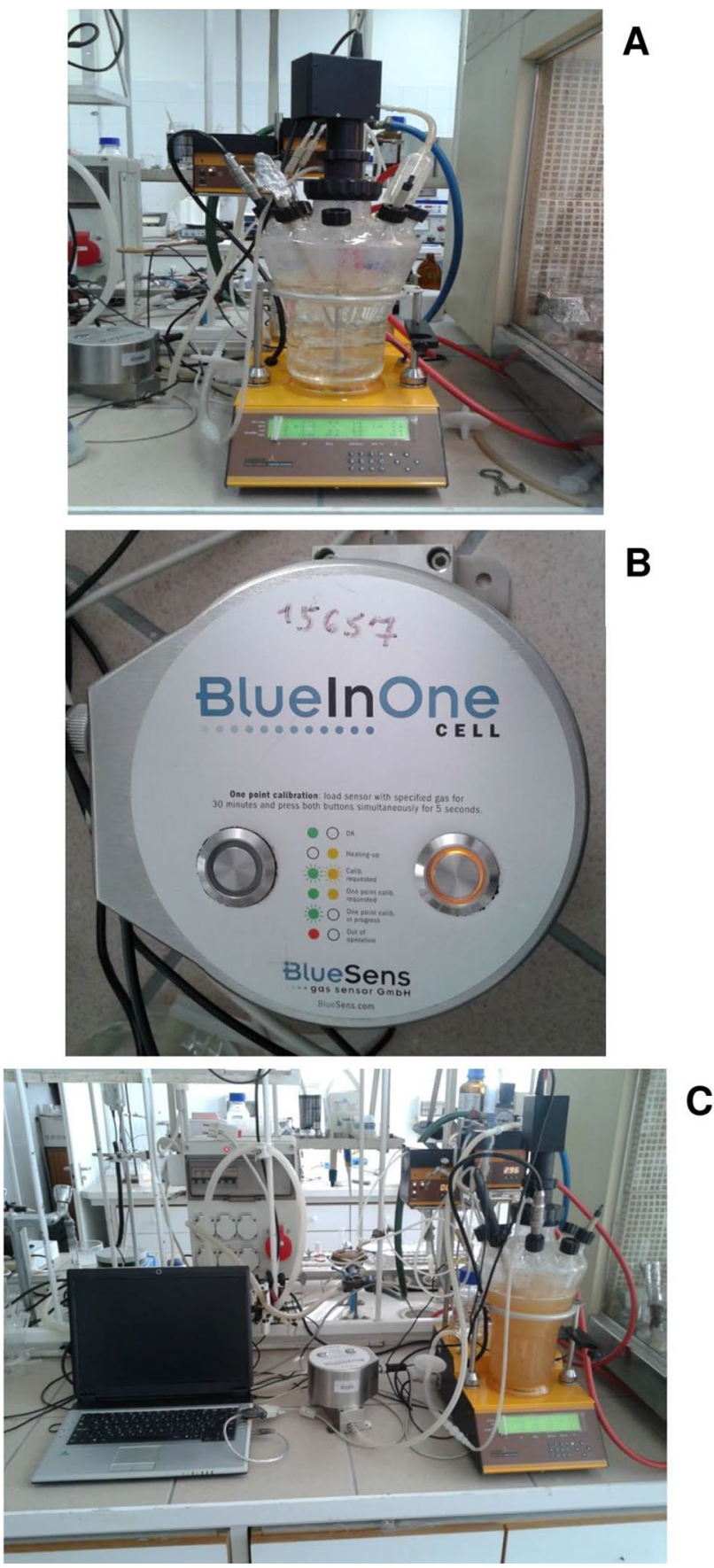

Fig. 1 The elements of the fermentation system in this study for the production of itaconic acid. a The bioreactor; $\mathbf{b}$ on-line $\mathrm{CO}_{2}$ sensor; $\mathbf{c}$ the bioreactor in operation

conditions, continuous aeration was employed via sterile membrane filters with air at a flow rate of $2 \mathrm{~L}$ (STP) $\mathrm{min}^{-1}$, providing $6.5 \mathrm{mg} / \mathrm{L}$ initial DO. The process temperature was set to $37^{\circ} \mathrm{C}$ and the agitation rate was $2 \mathrm{~Hz}$ (with stirring discs attached to a central, up and down moving shaft). The $\mathrm{pH}$ was controlled at $3 \pm 0.2$.

\section{Analytical Methods}

High-Performance Liquid Cromatography (HPLC) was applied to measure itaconic acid throughout the process with Young Lin Instrument Co., Ltd. (YL9100-type) device. In essence, it was equipped with a Hamilton HPLC column (15 $\mathrm{cm}$ in length, $4.6 \mathrm{~mm}$ inner diameter, $5 \mu \mathrm{m}$ particle size) and a UV/VIS detector. Gradient elution was applied ( $2 \mathrm{~mL} / \mathrm{min}$ flow rate) with a mobile phase consisting of A $\left(0.01 \mathrm{M} \mathrm{H}_{2} \mathrm{SO}_{4}\right)$ and $\mathrm{B}$ (methanol) as follows: $2 \mathrm{~min}-100 \%$ A; 5 min- $50 \%$ A, $50 \%$ B; 8 min-20\% A, $80 \%$ B. The raw samples were pretreated by $0.22 \mu \mathrm{m}$ PVDF membrane filtration and $1000 \times$ diluted afterwards with $0.01 \mathrm{M} \mathrm{H}_{2} \mathrm{SO}_{4}$.

A BlueInOne cell (BlueSens, Germany) (Fig. 1b) was installed to make the bioreactor system complete (Fig. 1c) in order to real-time monitor the $\mathrm{CO}_{2}$ concentration in the off-gas (https://www.bluesens.com/products/all-gas-sensors/ blueinone-cell/, accessed on 10.01.2019).

\section{Kinetic Evaluation of Itaconic Acid Fermentation}

The modified Gompertz-model (Eq. 1) —applied successfully in our previous paper [30] — was used to deliver the primary kinetic parameters of the batch process, which is based on the analysis of progress curves e.g. presented in Fig. 2a.

$I A(t)=P \exp \left\{-\exp \left[\frac{R_{m} e}{P}(\lambda-\mathrm{t})+1\right]\right\}$

where $I A(t)$ is the measured concentration of IA $(\mathrm{g} / \mathrm{L})$ in the reactor at time $t(\mathrm{~h}) ; P$ is the total IA production potential $(\mathrm{g} / \mathrm{L}) ; R_{m}$ is the maximal IA production rate $(\mathrm{g} / \mathrm{L}$ day), $\lambda$ is the lag-phase time (days) and $e$ is 2.718 . The least-squares regression method was employed via the Solver tool in MS Excel 2010 to attain the best model fitting to the experimental data.

\section{Results and Discussion}

\section{Assessment of Itaconic Acid Production: Titer, Yield, Productivity}

The IA concentrations obtained at different spots of the fermentation are listed in Table 1, meanwhile the corresponding time course is demonstrated in Fig. 2a.

As it can be seen, the peak IA concentration was reached by the 10th day, with a value of $26.3 \mathrm{~g} / \mathrm{L}$. This is in good agreement with the model results shown in Table 1, projecting the maximal IA titer as $28.1 \mathrm{~g} / \mathrm{L}$. In the literature, IA titers with A. terreus 1960 strain ranging between 40 and $110 \mathrm{~g} / \mathrm{L}$ were reported by Karaffa et al. [17] using glucose, 
Fig. 2 Progress curves for itaconic acid production. a Fermentation pattern for the whole bioreactor operation; $\mathbf{b}$ the $\mathrm{CO}_{2}$ evolution as a function of time. Blue diamonds: $\mathrm{CO}_{2}$ concentration; green triangles: itaconic acid concentration

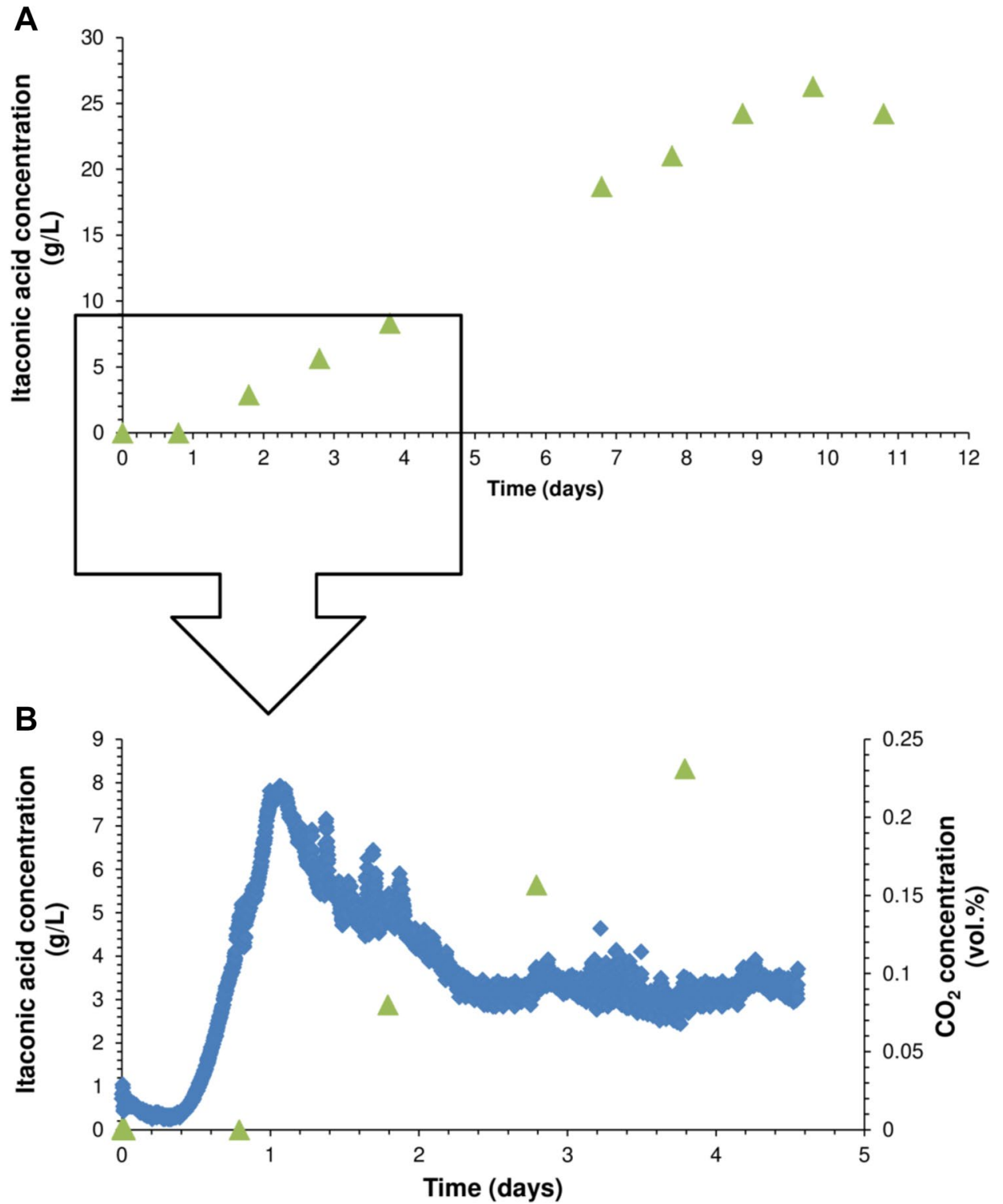

while Kocabas et al. [27] obtained $18 \mathrm{~g} / \mathrm{L}$ from glucose containing media tested in biorefinery concept. Accordingly, though the maximum IA titer is a function of many factors that are different from one study to another, our present results are in the same order of magnitude of the already published data and thus, comparable with those.

In fact, based on the amount of substrate available, the largest IA yield achieved was $0.3 \mathrm{~mol} \mathrm{IA} / \mathrm{mol}$ glucose, which is equivalent to $0.22 \mathrm{~g} \mathrm{IA} / \mathrm{g}$ glucose. According to theoretical calculations, the highest attainable yield could be $0.72 \mathrm{~g}$ IA/g glucose with $A$. terreus [31]. Certain batch studies using Aspergillus spp. such as Kuenz et al. [32] and Kautola et al. [33] reported IA yields as $0.62 \mathrm{~g} \mathrm{IA} / \mathrm{g}$ glucose (under optimized conditions) and $0.54 \mathrm{~g} \mathrm{IA} / \mathrm{g}$ glucose, respectively. In addition, Riscaldati et al. [34] obtained $0.21-0.53 \mathrm{~g} \mathrm{IA} / \mathrm{g}$ glucose with A. terreus NRRL 1960, depending on the circumstances of the fermentation. From these examples, it would appear that although the yield in our current investigation is comparable to the literature, there could be space for process enhancement via the further optimization of the operating settings. This can be the subject of another work in our research sequence.

Besides yield, the productivity (g IA/L $\mathrm{h}$ ) is an additional important measure of fermentation performance, which is calculated from the reactor size (working volume) as well as the time needed to get a particular quantity of IA. Actually, for an efficient process, both the yield (expressing the selectivity of the biological transformation towards the product of interest) and productivity should be as high as possible [35]. In this work, the overall productivity of $0.1 \mathrm{~g} \mathrm{IA} / \mathrm{L} \mathrm{h}$ was possible to achieve. Similar to the case of IA yields discussed above, other papers presented values 
Table 1 Itaconic acid profile of the fermentation

\begin{tabular}{lll}
\hline Time (days) & Itaconic acid concentration $(\mathrm{g} / \mathrm{L})$ \\
\hline 0 & 0 & \\
0.8 & 0 & \\
1.8 & 2.9 \\
2.8 & 5.6 \\
3.8 & 8.3 & \\
6.8 & 18.7 & \\
7.8 & 21 \\
8.8 & 24.2 & $\lambda$ (days) \\
9.8 & 26.3 \\
10.8 & 24.2 & 1.52 \\
\hline $\mathrm{P}(\mathrm{g} / \mathrm{L})$ & $\mathrm{R}_{\mathrm{m}}(\mathrm{g} / \mathrm{L}$ day $)$ \\
\hline 28.1 & 3.83 &
\end{tabular}

being either higher or nearly the same, such as $0.51 \mathrm{~g} / \mathrm{L} \mathrm{h}$ by Kuenz et al. [32] and $0.12-0.41 \mathrm{~g} / \mathrm{L}$ h by Riscaldati et al. [34]. Therefore, it can be concluded that in a follow-up study, where the conditions for IA formation are optimized considering the first outcomes we demonstrate herewith, the productivity could be improved along with IA titer and yield.

\section{Bioprocess Evaluation Considering On-Line $\mathrm{CO}_{2}$ Measurement}

To analyze the fermentation kinetics, data plotted in Fig. 2a were subjected to the modified Gompertz-model (Eq. 1) and the duration of lag-phase $(\lambda)$ could be estimated. As indicated in Table 1, it took 1.52 days for the IA production to get started. Additionally, in Fig. 2b, the progress curve for $\mathrm{CO}_{2}$ concentration in the bioreactor off-gas is illustrated. It can be deduced that $\mathrm{CO}_{2}$ formation commenced earlier than IA production and reached to a peak (0.22 vol\%) 1-1.2 day after process start-up. Thereafter, a gradual decrease was observed and as a result, $\mathrm{CO}_{2}$ content were quite stabilized after 2.2 days until the end of 4 th days (the point until which it was monitored) at $0.1 \mathrm{vol} \%$.

In Fig. 3, a general time profile for batch fermentation is shown where the product formation is linked to microbial proliferation. Hence, it can be seen that the extent of biomass growth and $\mathrm{CO}_{2}$ (as gaseous metabolite) evolution rate should be in relationship with the substrate to product conversion intensity. However, in accordance with the discussion above related to Fig. $2 \mathrm{a}$, b, the $\mathrm{CO}_{2}$ formation curve does not perfectly match the IA production pattern on the grounds of the apparent delay. This could make sense, if we consider that not all metabolic pathways leading to $\mathrm{CO}_{2}$ release are connected to IA production. From this, it is to assume that it deserves further examination whether the $\mathrm{CO}_{2}$

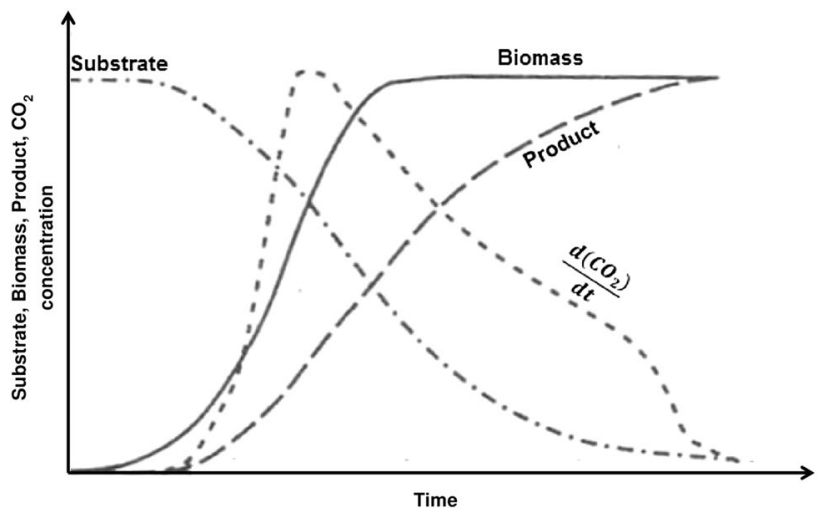

Fig. 3 An exemplary time profile of batch fermentation where product formation is attached to biomass growth

monitoring could be used as an indicator for the active biomass and/or its concentration during itaconic acid fermentation by A. terreus. For instance, $\mathrm{Ng}$ et al. [20] found that ergosterol as a metabolite released by fungi such as Aspergillus niger in the course of cell growth could show a reliable correlation with the carbon dioxide production, which was actually considered as an indicator of biomass growth. Therefore, on these grounds, experiments were planned to reveal whether, as already emphasized, $\mathrm{CO}_{2}$ formation could be used to assess biomass growth with A. terreus. The first results are observable in Fig. 4, showing the quantity of $\mathrm{CO}_{2}$ produced as a function of biomass growth for $A$. terreus strain. The plotted data are promising as a linear-type relationship can be suggested between these variables. Hence, the methodology of $\mathrm{CO}_{2}$ measurement is worthy for further investigation to validate the range and circumstances where it could be applicable with fair reliability to evaluate the growth of A. terreus.

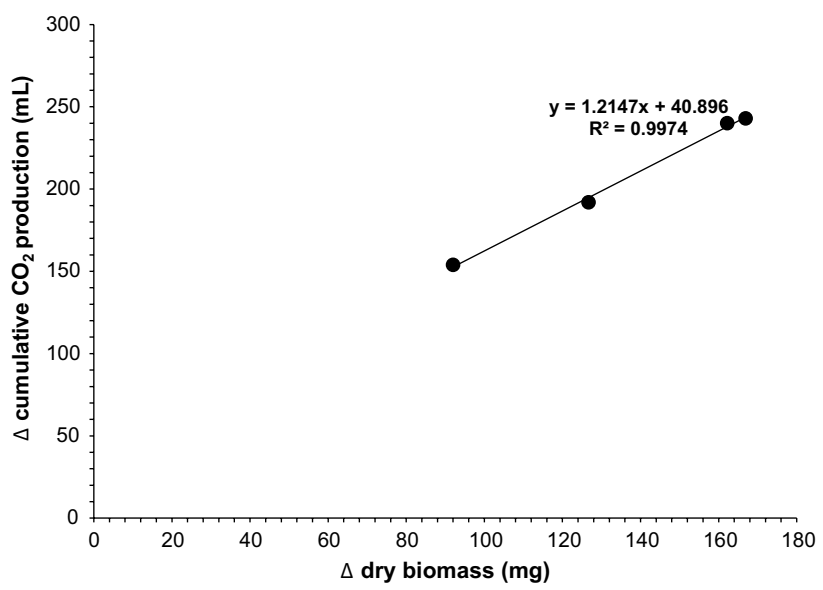

Fig. 4 Experimental correlation between $\mathrm{CO}_{2}$ formation and biomass growth of A. terreus 


\section{Conclusions}

In this research, itaconic acid was successfully produced by $A$. terreus from glucose, as renewable carbohydrate. The batch fermentation data underwent a kinetic evaluation and primary information to characterize the bioprocess was delivered. Besides, the assessment indicated that the itaconic acid generation performance in terms of its achievable titer, yield and productivity was comparable to the literature data, but further efforts shall be required for optimization. The biological conversion was followed by realtime measuring the $\mathrm{CO}_{2}$ release and it turned out that this approach may have a potential to monitor fungal biomass growth. This will have to be addressed more deeply in a future study.

Acknowledgements Open access funding provided by University of Pannonia (PE). This research was supported by the National Research, Development and Innovation Fund project OTKA K 119940 entitled "Study on the electrochemical effects of bioproduct separation by electrodialysis" and by the financial support of Széchenyi 2020 within project EFOP-3.6.1-16-2016-00015.

Open Access This article is distributed under the terms of the Creative Commons Attribution 4.0 International License (http://creativeco mmons.org/licenses/by/4.0/), which permits unrestricted use, distribution, and reproduction in any medium, provided you give appropriate credit to the original author(s) and the source, provide a link to the Creative Commons license, and indicate if changes were made.

\section{References}

1. Yang, L., Lübeck, M., Lübeck, P.S.: Aspergillus as a versatile cell factory for organic acid production. Fungal Biol. Rev. 31, 33-49 (2017)

2. Jang, Y.S., Kim, B., Shin, J.H., Choi, Y.J., Choi, S., Song, C.W., et al.: Bio-based production of C2-C6 platform chemicals. Biotechnol. Bioeng. 109, 2437-2459 (2012)

3. El-Imam, A.A., Du, C.: Fermentative itaconic acid production. J. Biodivers. Biopros. Dev. 1, 119 (2014). https://doi.org/10.4172/ ijbbd.1000119

4. Saha, B.C.: Emerging biotechnologies for production of itaconic acid and its applications as a platform chemical. J. Ind. Microbiol. Biotechnol. 44, 303-315 (2017)

5. Dwiarti, L., Otsuka, M., Miura, S., Yaguchi, M., Okabe, M.: Itaconic acid production using sago starch hydrolysate by Aspergillus terreus TN484-M1. Bioresour. Technol. 98, 3329-3337 (2007)

6. Lai, L.S.T., Hung, C.S., Lo, C.C.: Effects of lactose and glucose on production of itaconic acid and lovastatin by Aspergillus terreus ATCC 20542. J. Biosci. Bioeng. 104, 9-13 (2007)

7. Mondala, A.H.: Direct fungal fermentation of lignocellulosic biomass into itaconic, fumaric, and malic acids: current and future prospects. J. Ind. Microbiol. Biotechnol. 42, 487-506 (2015)

8. Pedroso, G.B., Montipó, S., Mario, D.A.N., Alves, S.H., Martins, A.F.: Building block itaconic acid from left-over biomass. Biomass Convers. Biorefinery 7, 23-35 (2017)

9. De Pretto, C., Giordano, R.L.C., Tardioli, P.W., Costa, C.B.B.: Possibilities for producing energy, fuels, and chemicals from soybean: a biorefinery concept. Waste Biomass Valorization $\mathbf{9}$, 1703-1730 (2018)

10. Sarker, T.C., Azam, S.M.G.G., Bonanomi, G.: Recent advances in sugarcane industry solid by-products valorization. Waste Biomass Valorization 8, 241-266 (2017)

11. Ramos, J.L., Udaondo, Z., Fernández, B., Molina, C., Daddaoua, A., Segura, A., et al.: First- and second-generation biochemicals from sugars: biosynthesis of itaconic acid. Microb. Biotechnol. 9, 8-10 (2016)

12. Cartensen, F., Klement, T., Büchs, J., Melin, T., Wessling, M.: Continuous production and recovery of itaconic acid in a membrane bioreactor. Bioresour. Technol. 137, 179-187 (2013)

13. López-Garzón, C.S., Straahof, A.J.J.: Recovery of carboxylic acids produced by fermentation. Biotechnol. Adv. 32, 873-904 (2014)

14. Magalhães Jr., I.A., de Carvalho, J.C., Medina, J.D.C., Soccol, C.R.: Downstream process development in biotechnological itaconic acid manufacturing. Appl. Microbiol. Biotechnol. 101, 1-12 (2017)

15. Varga, V., Bélafi-Bakó, K., Vozik, D., Nemestóthy, N.: Recovery of itaconic acid by electrodialysis. Hung. J. Ind. Chem. 46, 43-46 (2018). https://doi.org/10.1515/hjic-2018-0017

16. Hevekerl, A., Kuenz, A., Vorlop, K.D.: Influence of the $\mathrm{pH}$ on the itaconic acid production with Aspergillus terreus. Appl. Microbiol. Biotechnol. 98, 10005-10012 (2014)

17. Karaffa, L., Díaz, R., Papp, B., Fekete, E., Sándor, B., Kubicek, C.P.: A deficiency of manganese ions in the presence of high sugar concentrations is the critical parameter for achieving high yields of itaconic acid by Aspergillus terreus. Appl. Microbiol. Biotechnol. 99, 7937-7944 (2015)

18. Li, A., Pfelzer, N., Zuijderwijk, R., Punt, P.: Enhanced itaconic acid production in Aspergillus niger using genetic modification and medium optimization. BMC Biotechnol. 12, 57 (2012)

19. Shin, W.S., Lee, D., Kim, S., Jeong, Y.S., Chun, G.T.: Application of scale-up criterion of constant oxygen mass transfer coefficient $(\mathrm{kLa})$ for production of itaconic acid in a $50 \mathrm{~L}$ pilot-scale fermentor by fungal cells of Aspergillus terreus. J. Microbiol. Biotechnol. 23, 1445-1453 (2013)

20. Ng, H.E., Raj, S.S.A., Wong, S.H., Tey, D., Tan, H.M.: Estimation of fungal growth using the ergosterol assay: a rapid tool in assessing the microbiological status of grains and feeds. Lett. Appl. Microbiol. 46, 113-118 (2008)

21. Seitz, L.M., Sauer, D.B., Burroughs, R., Mohr, H.E., Hubbard, J.D.: Ergosterol as a measure of fungal growth. Phytopathology 69, 1202-1203 (1979)

22. Banerjee, U.C., Chisti, Y., Moo-Young, M.: Spectrophotometric determination of mycelial biomass. Biotechnol. Tech. 7, 313-316 (1993)

23. Yoon, J.H., Shin, J.H., Park, J.H., Park, T.H.: Effect of light intensity on the correlation between cell mass concentration and optical density in high density culture of a filamentous microorganism. Korean J. Chem. Eng. 32, 1842-1846 (2015)

24. Owens, J.D., Thomas, D.S., Thompson, P.S., Timmerman, J.W.: Indirect conductimetry: a novel approach to the conductimetric enumeration of microbial populations. Lett. Appl. Microbiol. 9, 245-249 (1989)

25. Sawai, J., Yoshikawa, Y.: Measurement of fungi by an indirect conductimetric assay. Lett. Appl. Microbiol. 37, 40-44 (2003)

26. Gyamerah, M.: Factors affecting the growth form of Aspergillus terreus NRRL, in relation to itaconic acid fermentation. Appl. Microbiol. Biotechnol. 44(1995), 356-361 (1960)

27. Kocabas, A., Ogel, Z.B., Bakir, U.: Xylanase and itaconic acid production by Aspergillus terreus NRRL, within a biorefinery concept. Ann. Microbiol. 64(2014), 75-84 (1960) 
28. Navale, G.R., Thripuranthaka, M., Late, D.J., Shinde, S.S.: Antimicrobial activity of $\mathrm{ZnO}$ nanoparticles against pathogenic bacteria and fungi. JSM Nanotechnol. Nanomed. 3, 1033 (2015)

29. Komáromy, P., Bakonyi, P., Kucska, A., Tóth, G., Gubicza, L., Bélafi-Bakó, K., Nemestóthy, N.: Optimized pH and its control strategy lead to enhanced itaconic acid fermentation by Aspergillus terreus on glucose substrate. Fermentation 5, 31 (2019). https ://doi.org/10.3390/fermentation5020031

30. Nemestóthy, N., Bakonyi, P., Rózsenberszki, T., Kumar, G., Koók, L., Kelemen, G., et al.: Assessment via the modified Gompertzmodel reveals new insights concerning the effects of ionic liquids on biohydrogen production. Int. J. Hydrog. Energy 43, 1891818924 (2018)

31. Klement, T., Büchs, J.: Itaconic acid-a biotechnological process in change. Bioresour. Technol. 135, 422-431 (2013)

32. Kuenz, A., Gallenmüller, Y., Willke, T., Vorlop, K.D.: Microbial production of itaconic acid: developing a stable platform for high product concentrations. Appl. Microbiol. Biotechnol. 96, 1209$1216(2012)$
33. Kautola, H., Vahvaselka, M., Linko, Y.Y., Linko, P.: Itaconic acid production by immobilized Aspergillus terreus from xylose and glucose. Biotechnol. Lett. 7, 167-172 (1985)

34. Riscaldati, E., Moresi, M., Federici, F., Petruccioli, M.: Effect of $\mathrm{pH}$ and stirring rate on itaconate production by Aspergillus terreus. J. Biotechnol. 83, 219-230 (2000)

35. Kumar, G., Bakonyi, P., Periyasamy, S., Kim, S.H., Nemestóthy, N., Bélafi-Bakó, K.: Lignocellulose biohydrogen: practical challenges and recent progress. Renew. Sustain. Energy Rev. 44, 728-737 (2015)

Publisher's Note Springer Nature remains neutral with regard to jurisdictional claims in published maps and institutional affiliations. 